Goldschmidt 2021 Abstract

https://doi.org/10.7185/gold2021.5477

\section{Water in the Early Paleozoic lithospheric mantle beneath the North China Craton: Constraint from olivine in the Mengyin kimberlites}

YANG GAO, YONG-FENG WANG, DA-PENG WEN, HAIJIN XU AND JUNFENG ZHANG

China University of Geosciences (Wuhan)

Presenting Author: ygao@cug.edu.cn

Water introduced by subduction of the Paleo-Pacific oceanic slab has been suggested to play a significant role in the lithospheric thinning of the North China craton (NCC). However, the water contents in the lithospheric mantle beneath the NCC prior to its thinning still remain unknown, which casts doubt on the validity of this view. Here we report the first hydrogen $(\mathrm{H})$ concentrations in olivine from the Paleozoic Mengyin kimberlites from the eastern NCC. Petrographic observations (anhedral to rounded grain shape, multiple grains, intracrystalline plasticity, garnet inclusion, and the presence of tabular olivine) and mineral chemistry (variable Fo contents, and low $\mathrm{Ca}$ and high $\mathrm{Ni}$ contents) point to that the studied olivine grains are xenocrysts originated from the disaggregation of mantle-derived peridotites rather than phenocrysts crystallizing from the kimberlite magma. The $\mathrm{H}$ concentrations determined by Fourier transform infrared (FTIR) spectroscopy in 225 out of 273 olivine grains showing visible $\mathrm{OH}$ absorption bands range from 8 to 307 wt ppm. $\mathrm{H}$ diffusional loss in some olivine grains is manifested by inhomogeneous $\mathrm{H}$ distribution (higher $\mathrm{H}$ concentrations in the cores and lower in the rims) and no detectable $\mathrm{OH}$ bands. However, most of the reported $\mathrm{H}$ concentrations likely reflect the in-situ hydration state of lithospheric mantle beneath the NCC. Such high $\mathrm{H}$ concentrations in the Paleozoic lithospheric mantle beneath the NCC are unexpected considering that it had experienced high degrees of melt depletion, but are comparable to those reported for other cratons worldwide, except the Tanzanian craton. We presume that the high $\mathrm{H}$ concentrations in the Mengyin olivine were caused by metasomatism by asthenosphere-derived melts and olivine grains with the highest $\mathrm{H}$ concentrations most likely came from the lithosphereasthenosphere boundary. This metasomatism-controlled hydration should be local; otherwise, the water-weakened mantle root of the NCC will be delaminated by the convecting asthenosphere, leading to its thinning in the Paleozoic, which contradicts with the existence of a thick $(>200 \mathrm{~km})$ lithospheric keel at that time. Therefore, our data confirm that local metasomatism will not cause widespread lithospheric thinning.

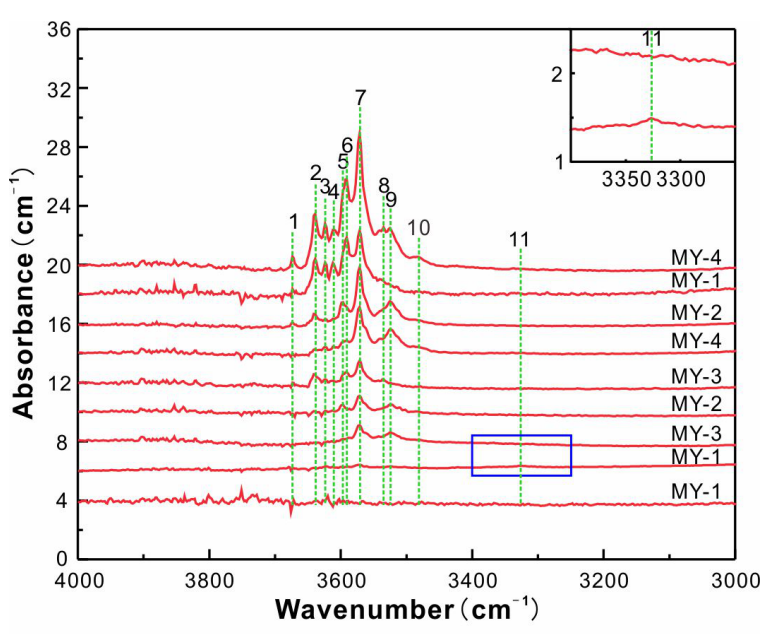

Figure 1

Table 1

Summary of FTIR Analyses for Olivine Phenocrysts Showing Visible OH Absorption Bands

\begin{tabular}{|c|c|c|c|c|}
\hline Sample & $\mathrm{n}$ & $t(\mu \mathrm{m})$ & Integrated Absorbance $\left(\mathrm{cm}^{-1}\right)$ & $C_{\mathrm{H}_{2} \mathrm{O}}(\mathrm{wt} \mathrm{ppm})$ \\
\hline MY-1 & 48 & $94-290$ & $0.44-7.62$ & $11-231$ \\
\hline MY-2 & 18 & 171-182 & $0.56-3.45$ & $19-115$ \\
\hline MY-3 & 38 & $122-336$ & $0.30-5.80$ & $8-163$ \\
\hline MY-4 & 122 & $127-238$ & $0.40-7.47$ & $14-307$ \\
\hline
\end{tabular}

n, number of measured grains; $t$, sample thickness; $C_{\mathrm{H}_{2} \mathrm{O}}, \mathrm{H}$ concentration in olivine calculated using the method detailed in Matveev \& Stachel (2007). 